\title{
Biotelemetry and data logger system for measuring behavior and ecology of marine organisms
}

\author{
YOSHINORI MIYAMOTO, ${ }^{1}$ and YASUHIKO NAITO ${ }^{2}$ \\ 'Department of Marine Science and Technology, Tokyo University of Fisheries, 4-5-7, Minato, Tokyo, 1088477, \\ Japan (miyamoto@tokyo-u-fish.ac.jp), and ${ }^{2}$ National Institute of Polar Research, 1-9-10, Itabashi, Tokyo, \\ 1738515, Japan
}

SUMMARY: The coexistence of marine mammals, seabirds, sea turtles and fish is an important factor for future fishery continuation. However, in the underwater, it is difficult to observe free-ranging behavior of marine organisms in spite of present-day technical progress. Research on the behavior, ecology, and physiology of marine organisms under natural conditions is limited, except for the information acquired from marine organisms by direct observation and direct measurement. Therefore, biotelemetry is useful technique to observe the habits of marine mammals needed for coexistence with the fisheries. The technology of biotelemetry is developed with use of the communication technology using the artificial satellite, the development of a micro-data logger that carried various sensors by ultra miniaturization of electronic products, etc. Thereby, according to the research purpose and the target marine organisms, we can choose the system of various kinds.

\section{KEYWORDS: biotelemetry, behavior, micro-data logger, marine organisms}

\section{INTRODUCTION}

How can we detect the biological phenomena such as feeding, hiding or other movements that occur underwater? How can we visualize the biological events that appear beneath the surface without using advanced technical supports? In modern science very precise and detailed analysis on the unknown phenomena from various aspects is essential. Unless the issues of the technical difficulty of measurements or visualization of the underwater phenomena are not solved, understanding of the marine ecosystem for global change or issue of bycatch problems for conservation will be difficult.

To contribute to this matter researchers have tackled this problem and various methods have been tried and devised. Firstly, ordinal tags have been attached to the marine organism to know the direction and range of their movements. However, the data obtained are only about the release position and the recapture position, and further it is unknown how they behave during the migration.

Considering this problem, the biotelemetry system has been developed, which uses a radio transmitter for chasing and tracking the animal movements more precisely. The system is only available when animals come to surface or in the fresh water area. Thus this system is used for tracking the marine mammals and marine birds such as penguins. The biotelemetry system is now used as satellite linked system that can cover a wide range.

Acoustic biotelemetry system is also developed as powerful tools to detect animals and their movements. This system is useful for following the movements of fish herds or schools. When we follow the individual movements, we need to attach the small transmitter (pinger) on the target animal and have to follow the signals from the fish pinger by the ship.

The third method researchers tried to develop is the data logger system. A very miniaturized data logger is attached to the animal body for monitoring the movements and data storage. Actually, three kinds of biotelemetry system (ultrasonic telemetry, micro-data logger and satellite telemetry) are used for observations on the marine organism.

The methods and results of three kinds of the biotelemetry system are shown in this paper.

\section{MATERIALS AND METHODS}

\section{Ultrasonic telemetry}

This biotelemetry system is the most effective to observe behavior in underwater. But this system needs time and a cost by chasing it by a ship. Instead of it, the system obtaining a position of the pinger three dimensionally using several transducers is developed. The tracking system was composed of an ultrasonic pinger, a four channel receiver, four transducers, an 8 bit single board computer with $\mathrm{ADC}$, a personal computer, an electronic magnetic compass and a DGPS receiving system (Fig. 1) 1)

As a separate system, this was composed of one master station and eight secondary stations and the ultrasonic pinger. Each secondary station is composed of a transducer, an ultrasonic transceiver and a radio transceiver. The master station's unit consists of eight channel radio 


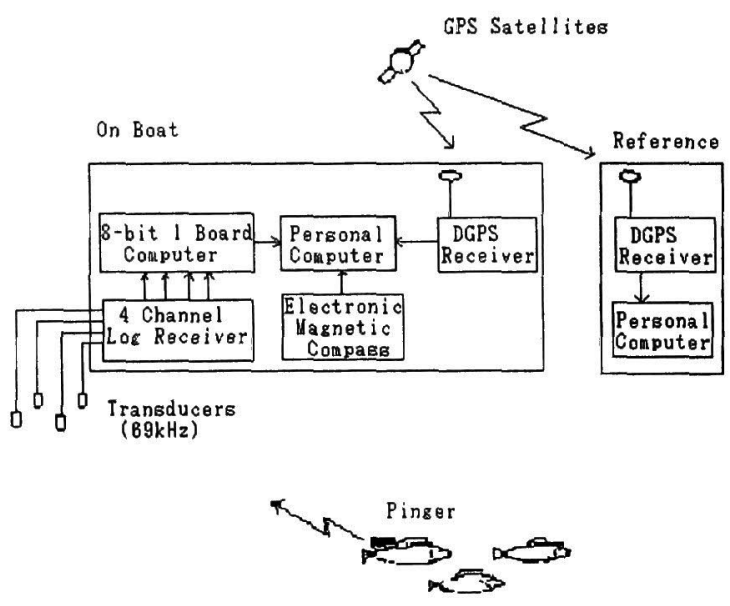

Fig.1 Configuration of fish tracking system at Tamanoura-wan, Nagasaki Prefecture (1994) ${ }^{1)}$

receivers, a radio transmitter and a personal computer ${ }^{2)}$.

In these systems, the bearings of the pinger are calculated using the short base line by measuring the receiving time differences of a pulse between channels. The distance resolution of this system was about $1 \mathrm{~m}$. and the coverage of this system is within a radius of about $15 \mathrm{~m}$.

\section{Satellite telemetry}

This satellite telemetry system is called ARGOS system that requires the transmitter prepared for the performance of the ARGOS system. The ARGOS system is a data collection system by means of the meteorological satellite NOAA to collect the geological, oceanographical and environmental data remotely from the space using a PTT (ARGOS Platform Transmitter Terminal). PPT is lightweight and compact; most weigh less than $1 \mathrm{~kg}$ with some as little as $25 \mathrm{~g}$.

PPT positions are calculated several times a day and supplied to users at the ARGOS Global Processing Centers in Toulouse, France and Landover, MD, USA ${ }^{3)}$ For example, size of PPT is different with a dry cell, but depth sensor type is with length $=110 \mathrm{~mm}$, width $=50 \mathrm{~mm}$, height $=30 \mathrm{~mm}$, weight $=170 \mathrm{~g}$ in air and dry cell life 150 days (transmission on alternate day).

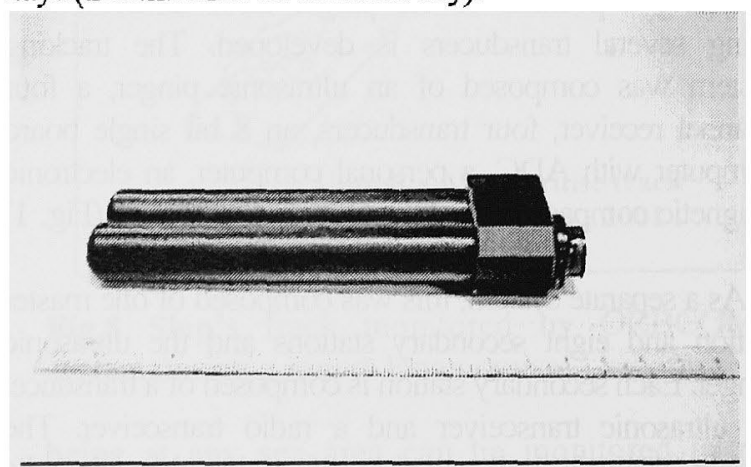

Fig2 Ulrasmall fish finding logper

\section{Micro-data logger}

The first effort to miniaturization has been made in developing the data loggers, which remarkably increases the utility of data loggers. Purpose of the miniaturization is to diminish the drag on the animals and to secure normal behavior. It will contribute to expand the opportunity to apply this technique to a variety of animals.

The micro-data logger is composed of housing, battery, sensors and logger. As housing we selected an aluminum tubular case because of its lightweight and low cost. Pressure durability of the housing is adequate up to a depth of $500 \mathrm{~m}^{4}$. The aluminum housing is coated with black alumite to prevent oxidation. The logger is composed of two boards: an analog board connected to the sensors and a memory board on which the memory chip, CPU and quartz for the clock are mounted.

Various loggers, which can acquire the ecology information that a biologist demands, have been developed as follows.

- TDL(Temperature and time Depth Logger)

- TTL (Double Temperature Logger)

- STL(Stomach Temperature Logger)

- ECGL(Electro-CardioGraph Logger)

- PDT (Velocity (Propeller), Depth and Temperature logger)

- PD2G (Velocity (Propeller), Depth and 2-axis Gravity logger)

- DLC (time Depth, Light and Conductivity logger)

- Ultra small fish finding logger(Fig,2)

- Digital still camera logger

The logger is attached to the back of diving animals using cable ties or quick-setting epoxy glue. All loggers can be programmed to record data at intervals and starting time for individual sensor. Data are recorded in the flash memory. Data from the loggers are downloaded into a computer for analysis.

\section{RESULTS AND DISCUSSION}

\section{Ultrasonic telemetry}

The striped jack bred was released at Tamanoura of Goto Islands, Nagasaki Prefecture, and the tracking observation was conducted in February 7, 1994). The observation instrument and system is shown in Fig. 1. Results are shown in Fig. 3. In this observation, the purpose was to observe behavior of the striped jack. Five fish were released, and the pinger was equipped with one of them. Three-dimensional movement of a striped jack was provided. This movement is confirmed by visual observation. 


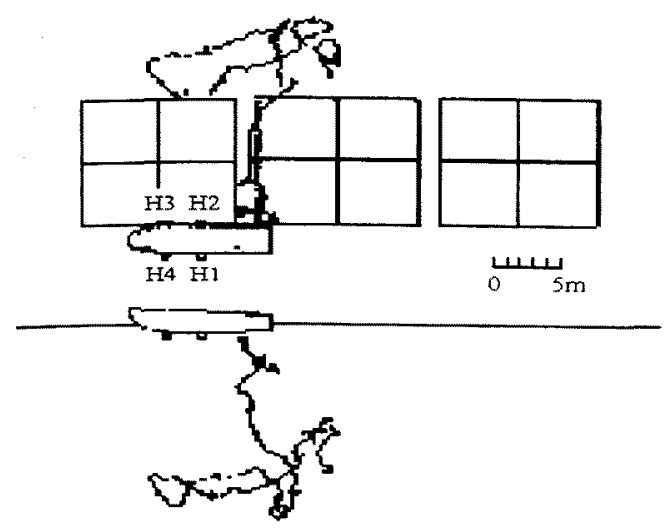

Fig 3 Movements of the striped jack after release in February 7 , 1994 during 10:45 to $10: 51$. The upper diagram is the plan view and the lower diagram the side view ${ }^{1}$ )

\section{Satellite telemetry}

Using ARGOS for an animal has been described earlier"). However, using marine mammals, there is high restriction about ARGOS. There is a paper that used this system for the seal and the penguin. The reason is that these animals remain in land or the sea surface for a long time ${ }^{6}$.

Evaluation in a fixed point of PPT that Kakihara et al. produced experimentally is introduced here. The inspection experiment of the positioning accuracy of PTT was done for three days in February 1994. The error quantity was different by distance of NOAA satellite, but the positioning accuracy was about $1.5 \mathrm{~km}$ on average.

\section{Micro-data logger with Radio tracking}

The study was conducted at Hukuro Cove colony, Langhovde about $25 \mathrm{~km}$ south of Syowa Station in Luitzow-Holm Bay, Antarctica. The experiments were carried out during late December 1995 to January 1996 in JARE $37^{7}$. The colony contained 150 breeding pairs of Adélie penguins. The penguin feed chicks between late Dec. and Feb. In Langhovde, water depth exceeds $100 \mathrm{~m}$ starting at about $0-2 \mathrm{~km}$ from shore. In Lützow-Holm bay, fast sea-ice develops during most part of year. In this area, during the Antarctic summer, open water appears first along the coast and then extends to areas offshore. Visible extent of open water and presence of ice-cracks and puddles around the Hukuro Cove was recorded.

The TDL recorded their diving behavior of the attached penguins in every 2 seconds continuously. To detect foraging areas, TDL and radio transmitters were attached simultaneously. We attached radio transmitters on the back of seven penguins using quick set epoxy glue. Each transmitter operated on a different frequency. The positions

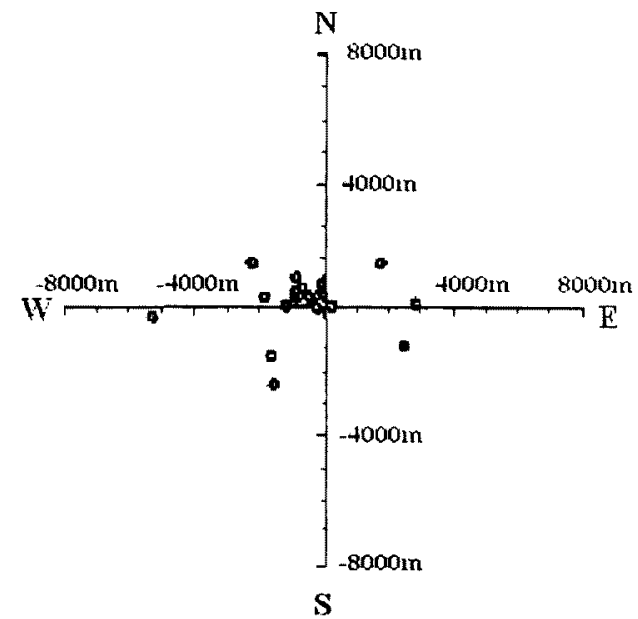

Fig.4 The distribution of the positioning accuracy in a fixed Doint of PTT

of penguins were determined by triangulation using two sets of receivers and seven element stuck Yagi-antennae. The antennae were mounted on 1-m tripods set on the tops of hills. Radio tracking was carried out for about 8 days between 9:00 - 19:00 every day between 2 - 4 January 1996, 12 - 14 January 1996 and 23 - 25 January 1996, scanning each frequency every 30 minute. Feeding sites were categorized as 1) tidal cracks along the coast line within $200 \mathrm{~m}$ of the land, 2) open water within $200 \mathrm{~m}$ of the small islets and 3) open waters around ice bergs more than $200 \mathrm{~m}$ distant from the land (Fig. 5).

At the same foraging position and same season, the diving pattem by an individual bird was similar (Fig. 6). Therefore, it was considered that there is effect of the

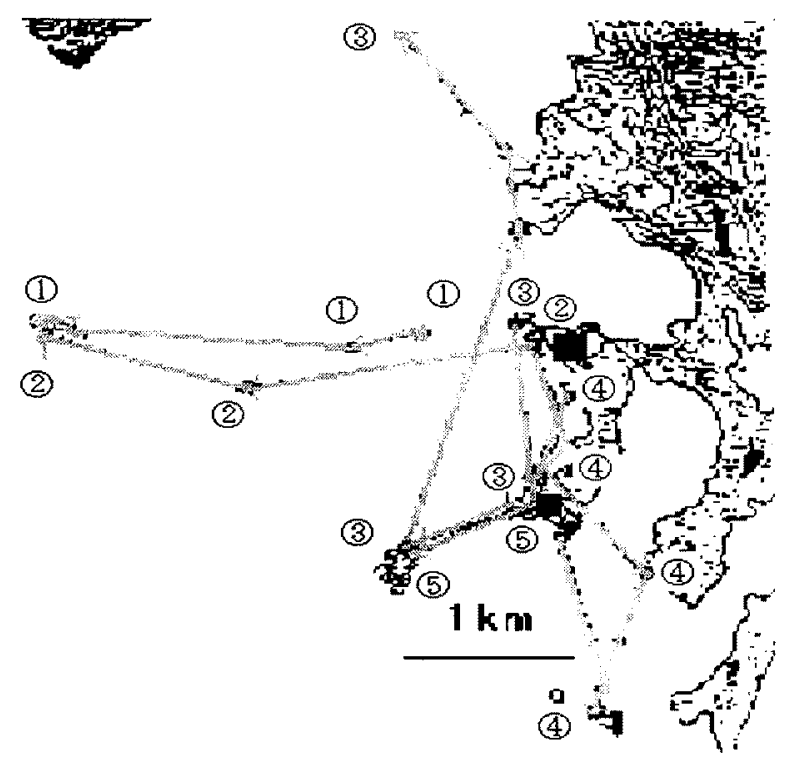

Fig.5 Results of the radio tracking in Langhovde, Lutzow-Holm Bay, Antarctica between 12 - 14 January 1996. The number of circle shows individual Adélie penguins. Marks of show the radio tracking antenna position ${ }^{7}$ 
foraging site selection, regardless of diving ability of the individual penguin. In this season, the study colony at the Hukuro Cove was heavily covered by fast sea-ice that automatically determined foraging site due to limited available cracks to dive. This condition of fast sea-ice regulated the food quantity and prey items.

\section{CONCULSION}

Three kinds of the biotelemetry techniques were described. By the advancement of the electronic devices, the biotelemetry technique has improved by leaps and bounds. But, there is a limit in use according to object animals in size and behavior pattern. We need to select the techniques considering the advantages and disadvantages of each technique.

The ultrasonic telemetry has a weakness that the observation area is limited, and is difficult to obtain the physiological information. In micro-data logger, the reoovering method of the logger is still an unsolved problem.

The diving animals could be chased using satellite telemetry. However, this telemetry cannot be used for fish that move underwater. For particular use of the communications, satellite of LEO (Low Earth Orbit, e.g. $\mathrm{ORBCOMM}^{8)}$ has started, and the satellite telemetry system will be further developed by this system in near future. The role of the satellite telemetry should be important, but the costs down of the instrument and the specification charges, the law deregulation on the instrument use are necessary.

The micro-data logger is more promising, but there are some problems to be solved. In addition to a sensor development, further miniaturization is required when used for smaller fishes and others. Weight of the logger is expected less than $2 \%$ of the body weight of fish and the minimum size of the present logger is $15 \mathrm{~g}$ in air and $8 \mathrm{~g}$ in water. Yet we have limitation in the selection of the study fish. The problem of recovery is the most difficult subject. At present recovery depends on fishery activities as ordinary tags. However, in this case it is strongly expected that unit price of micro data logger is reduced.

Three methods are complementary and it is effective to make up for each other's weak points. Therefore selection and combination of techniques case by case is one method to solve these problems at present. The study of the ocean and animals by the biotelemetry techniques and the study of animal physiology under ocean environment become more and more necessary in order to understand principle of life in ocean and how they survive the severe changes in ocean environment such as global change and marine pollution. The consideration on the disturbance on marine life by fisheries activities is also important. To diminish such disturbance we need to know much about life in ocean. Understanding of the habits of

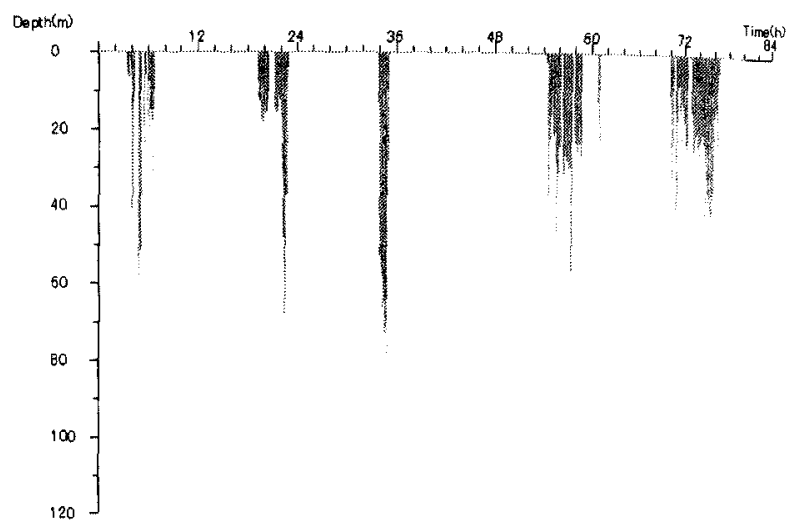

Fig.6 An example of the diving behavior of an Adelie penguin ${ }^{7}$

the wildlife in a fishing ground is indispensable to that purpose.

\section{ACKNOWLEDGMENT}

I am grateful to Dr. Toshiharu Kakihara (Tokyo University of Fisheries), Dr. Atsushi Tanimura (Mie University) and Dr. Yutaka Watanuki (Hokkaido University) for their helpful advice and timely guidance throughout this study. Dr. Katsufumi Sato (National Institute of Polar Research) and Dr. Akiko Kato (National Institute of Polar Research) provided useful suggestions.

\section{REFERENCES}

1. H. Jun, Y. Miyamoto, E. Hamada and Y. Nakamura: A new ultrasonic pinger system using synchronizing method for tracking fish, Nippon Suisann Gakkaishi, 1995,61(3), 369-374

2. Y. Miyamoto, H. Jun, E. Hamada and A. Tanimura: Development of an instrument for observing fish behavior under the sea ice using ultrasonic pinger near Syowa Station, 1995, Antarctic Record, 39(1), 49-67

3. Argos newsletter 54-APRIL 1999,24

4. Y. Naito: Development of a microdata tag for study of free ranging marine animals, 1997, Mem. Fac. Fish. Hokkaido Univ., 31-34

5. P. Jouventin and $\mathrm{H}$. Weimerskirch: Satellite tracking of wandering albatrosses, Nature, 343, 746-748 (1990)

6. A. Ancel, G. L. Kooyman, P. J. Ponganis, J. P. Gendner, J. Lignon, X. Mestre, N. Huin, P. H. Thorson, P. Robisson. and Y. Le Maho: Foraging behaviour of emperor penguins as a resource detector in winter and surmmer, 1992, Nature, 360, 336-338

7. Yutaka Watanuki, Yoshinori Miyamoto and Akiko Kato: Dive Bouts and Feeding Sites of Adélie Penguins Rearing Chicks in an Area with fast Sea-lce, 1999, Colonial Waterbirds, 22(1), 120-129.

8. ORBCOMM's:Website: http://wwworbommnel. 